\title{
CONSIDERAÇÕES SOBRE A METODOLOGIA A RESPEITO DA ALTERAÇÃO DA TEMPERATURA DO AR NO AMBIENTE URBANO: ESTUDO EM SÃO JOSÉ DOS PINHAIS/PR
}

\author{
Cristina de Araújo Lima 5 \\ Inês Moresco Danni-Oliveira6 \\ Susanne Cristine Pertschi ${ }^{7}$
}

\begin{abstract}
RESUMO
O presente artigo tem o propósito de demonstrar parte da pesquisa realizada, no município de São José dos Pinhais/PR, que avaliou o uso da análise de regressão linear simples para relacionar temperaturas do ar e o uso do solo em oito localidades da área urbana. Os dados de temperatura foram coletados por sensores HOBO RH/Temp, programados para armazenar as temperaturas a cada hora, durante aproximadamente trinta dias, na estação de verão. Posteriormente alguns atributos urbanos foram mensurados para que na seqüência, as informações pudessem ser associadas e analisadas. O método utilizado foi o estudo de caso, por meio da análise analítica e da correlação entre os atributos urbanos e as temperaturas dos abrigos. Os resultados indicaram temperaturas diferenciadas em algumas localidades que tem vinculação variada com os atributos urbanos quantificados. Quanto aos coeficientes de correlação encontrados, a maioria demonstrou-se baixo. Os resultados, por terem sido amostrais, não puderam homogeneizar a relação clima e padrão de ocupação no município, mas sim alertar para as futuras decisões de planejamento e gestão.
\end{abstract}

Palavras-chave: Planejamento Urbano, Conforto Ambiental, Clima Urbano, Monitoramento Térmico.

\section{ABSTRACT}

This article has the purpose of demonstrating part of the accomplished research, in the municipal district of São José dos Pinhais/PR, which evaluated the use of simple linear regression analysis to relate air temperature and land use in eight towns in the urban area.that related the temperatures of the air and the use of

\footnotetext{
${ }^{5}$ Profa. Dra., Dep. de Arquitetura e Urbanismo - UFPR. Centro Politécnico Caixa Postal 19011 - Cep 81531-990 - Curitiba - Pr - e-mail: cristinalimazk@ufpr.br

${ }^{6}$ Profa. Dra., Dep de Geografia - UFPR. Centro Politécnico Caixa Postal 19001 - CEP 81531-990 -

Curitiba - Pr - e-mail: inesmdo@ufpr.br

7 Mestre em Construção Civil, UFPR. Centro Politécnico Caixa Postal 19001 - CEP 81531-990 Curitiba - Pr - e-mail: susannepertschi@brturbo.com.br
} 
the soil in eight places of the urban area. The temperature data were collected by sensor HOBO RH/Temp, programmed to store the temperatures at every hour, during approximately thirty days, in the summer station. Later, some urban attributes were measured. After that, the information could be associated and analyzed. The method that was used was the study of case, by means of the analytic analysis and of the correlation between the urban attributes and the temperatures of the shelters. The results indicated temperatures differentiated in some places and this can be linked with the quantified urban attributes. Regarding the coefficients of correlation that were found, most of them were low. The results, for having been samples, were not enough to homogenize the relation between the climate and the occupation pattern in the municipal district, but it was possible to alert for the future planning decisions and administration.

Keywords: Urban Planning, Thermal Comfort, Urban Climate, Thermal

\section{INTRODUÇÃO}

Muitas são as mudanças ocorridas no meio ambiente decorrentes das ocupações nos centros urbanos. Um destes exemplos, segundo Oke (1991), diz respeito às alterações no clima, advindas do homem, que modifica as condições climáticas através da urbanização, industrialização, desmatamento, atividades agrícolas, drenagem e construção de lagos, entre outras ações, que impactam o meio ambiente principalmente as áreas urbanas. Devido a esses impactos, o clima nas áreas urbanas é normalmente muito diferente do clima nas áreas rurais.

Segundo Mascaró (1985, 1986) e Garcia (1992), os climas urbanos são caracterizados, em geral, pela grande influência que a superfície construída exerce sobre a atmosfera adjacente, ou seja, são decorrentes da urbanização dos centros urbanos, onde o uso excessivo de pavimento e concreto, os altos edifícios próximos entre si, a emissão de calor de condicionadores de ar e outras fontes de calor doméstico e a concentração de poluição induzem à modificação do clima original. Esses fatores em geral contribuem para o armazenamento de muito mais calor que a vegetação e a terra, ou seja, o meio natural não antropizado.

De acordo com Romero (2001) e Garcia (1992), um dos primeiros estudos sobre climatologia urbana, realizado em Londres, é atribuído a Luke Howard, em 1818. Outros estudos foram realizados por Renou (1862) e Hann (1897:1908), entre outros. Entretanto, inicialmente durante a Primeira Guerra Mundial foram desenvolvidos equipamentos para medição dos elementos do clima, quando também foram criados os serviços de meteorologia, climatologia. Até então os estudos restringiam-se ao campo térmico e principalmente às diferenças do clima nas áreas urbanas e rurais (MENDONÇA, 1994).

Após a Segunda Guerra Mundial, com as altas taxas de crescimento das cidades e das regiões metropolitanas no mundo, as pesquisas quanto aos climas urbanos avançaram consideravelmente, principalmente nos Estados Unidos, Europa e mais recentemente no Japão. Segundo Monteiro (2003), o marco teórico dos estudos sobre climas urbanos é atribuído a Landsberg, em 1956, 
com o seu trabalho "The Climate of Towns". Em 1965, Chandler, com seu estudo sobre o clima de Londres, merece destaque por ser considerado 0 primeiro estudo sobre clima de uma metrópole (GARCIA, 1992; MONTEIRO, 2003).

Todos esses estudos contribuem para minimizar os impactos negativos das ocupações nos grandes centros urbanos, podendo ser previstos pelo planejamento e objeto da gestão continuada, assim como as tendências de crescimento, o ordenamento do uso do solo, a formação de climas locais mais amenos, através de critérios técnicos da qualidade da ventilação, os efeitos da circulação local, a redução do vento e o controle da poluição do ar, sempre devem considerar os aspectos ambientais da região (KATZSCHNER, 1988).

Cabe, portanto, ao planejamento desenvolver estratégias e ações táticas que aliem o crescimento das cidades com o equilíbrio da qualidade ambiental, visando ambientes mais agradáveis e salubres nos centros urbanos. Isso significa dizer que além de incluir nos estudos do planejamento urbano os dados ambientais da região, especialmente os relacionados ao clima, tais como, temperatura, pluviometria, direção e intensidade dos ventos, entre outros, deve-se aplicá-los mais veementemente nas ações de planejamento (ELNAHAS, 1999). Dentre as questões relacionadas, é salientada a importância dos dados climáticos, que são responsáveis pelas alterações nos regimes de chuvas e fluxos de ventos, geram ilhas de calor e de frio, provocando o aumento no consumo de energia decorrente do uso de sistemas de climatização artificial das edificações.

\section{CENÁRIO DE ESTUDO - ÁREA URBANA DE SÃO JOSÉ DOS PINHAIS/PR}

São José dos Pinhais localiza-se na Região Metropolitana de Curitiba/PR (RMC). Possui dentre os municípios da RMC, uma das maiores taxas de crescimento populacional, tendo sido registrado no período de 1991 a 2000, 5,38\% (IBGE, 1991:2000). Para o mesmo período, foi registrado o crescimento de 1,39\% para o estado do Paraná (IBGE, 1991:2000). Quanto à população, o município, de acordo com dados do censo de 2000, possuía 204.316 habitantes (IBGE, 2000). Segundo a projeção do IBGE, para o ano de 2010 a população será de 339.891 habitantes. Quanto aos aspectos econômicos, o município de São José dos Pinhais é a terceira economia do Estado, perdendo apenas para Curitiba e Araucária (IPARDES, 2003).

O clima da região em que está situado o município de São José dos Pinhais é classificado como Clima Subtropical Úmido Mesotérmico, com verões frescos, invernos com ocorrências de geadas severas e freqüentes, não apresentando estação seca (MAACK, 1968). As temperaturas médias registradas nos meses mais quentes do ano no município são entre $27^{\circ} \mathrm{C}$ e $29^{\circ} \mathrm{C}$, e as dos meses mais frios entre $14^{\circ} \mathrm{C}$ e $16^{\circ} \mathrm{C}$ (SIMEPAR, 2004).

Considerando-se os aspectos urbanísticos, São José dos Pinhais possui áreas urbanizadas em contraposição com áreas verdes e livres, áreas industriais, áreas com alta, média e baixa densidade demográfica. A região central por ser antiga, não é verticalizada nem adensada, possuindo ainda várias áreas verdes e livres. 


\section{DIRETRIZES TEMPORAIS E ESPACIAIS DO ESTUDO DE CASO}

Para o monitoramento, foram construídos abrigos termométricos de $25 \times 25 \times 25$ centímetros, em madeira, com espessura de dois centímetros, com vários furos em quarenta e cinco graus (semelhante a venezianas) nas laterais e fundos, com a tampa superior fechada e fundo com dobradiça. Na seqüência, os abrigos foram revestidos externamente com papel alumínio, devido às propriedades térmicas desse revestimento. Cada abrigo recebeu internamente um datalogger do tipo HOBO H8RH/Temp, que, previamente calibrado, foi pendurado no centro da caixa e programado para registrar as temperaturas a cada hora, entre os dias 04 de dezembro de 2004 e 05 de janeiro de 2005, durante vinte e quatro horas por dia.

Para determinação dos locais de monitoramento, foram consideradas as premissas de Monteiro (1990), que defende que a escolha dos pontos para medição deve respeitar o critério de melhor representatividade da natureza ou do caráter peculiar da cidade escolhida. Diante disso, os oito pontos monitorados foram selecionados com base na morfologia urbana e na Lei de Uso e Ocupação do Solo e Sistema Viário (Lei n 10/2004) do município de São José dos Pinhais (figura 01), buscando áreas com diferentes usos e índices de ocupação sobrepostos com o sistema viário municipal(tabela 01).
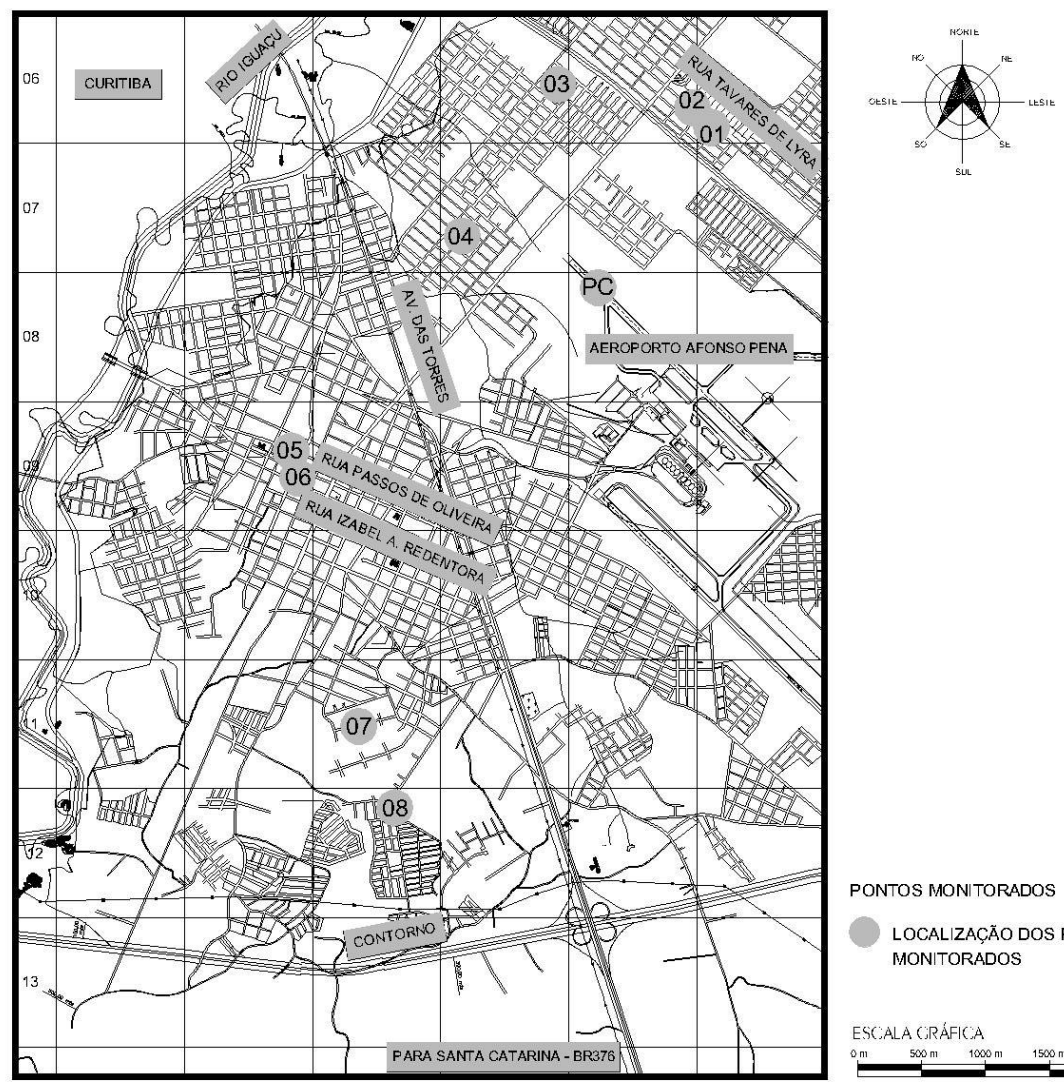

PONTOS MONITORADOS

LOCALIZAÇĀO DOS PONTOS MONITORADOS

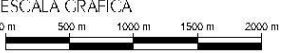

Figura 01. Localização dos pontos monitorados - dez.2004-jan.2005.

Com o objetivo de explicar as variações ocorridas nos pontos de medições entre si e entre esses e o ponto de controle, fez-se a análise 
quantitativa do entorno imediato onde foram fixados os abrigos (figura 02). Para isso, utilizou-se a área de $10.000 \mathrm{~m}^{2}$ (que corresponde a um raio de 56 metros, definido em função das quadras padrão de 100 metros) e de $49.000 \mathrm{~m}^{2}$ (que corresponde a um raio de 125 metros, definido em função das quadras padrão de 100 metros somadas com as caixas de rua de 14 metros) aproximadamente, para mensurar as porcentagens de ocupação do solo para cada ponto (tabela 02 e 03).

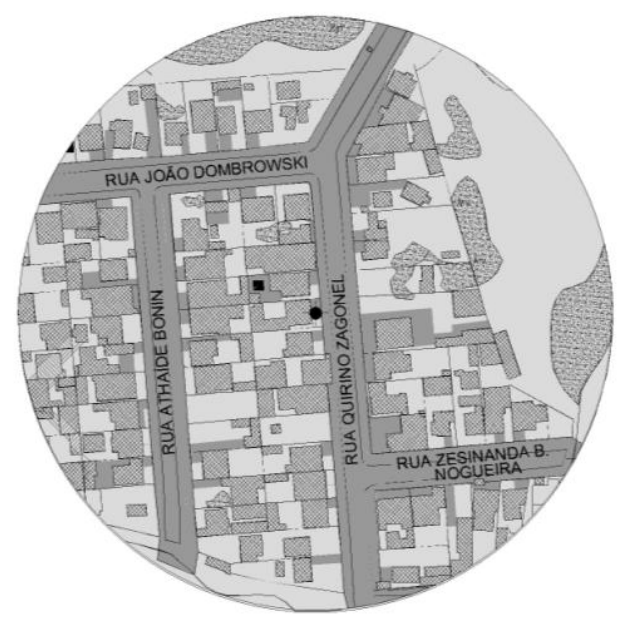

\begin{tabular}{|c|c|c|c|}
\hline & TIPO DE OCUPAÇĀO & ȦREA & PORCENTAGEM \\
\hline \multirow[t]{3}{*}{$\cdots$} & ÁREA CONSTRUIDA & $A=11.265,64 \mathrm{~m}^{2}$ & $22,95 \%$ \\
\hline & ÁREA LIVRE & $A=22.047,15 \mathrm{~m}^{2}$ & $44,91 \%$ \\
\hline & ÁREA PAVIMENTADA & $A=12.492,58 \mathrm{~m}^{2}$ & $25,45 \%$ \\
\hline \multirow[t]{4}{*}{ 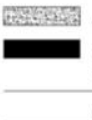 } & ÁREA VERDE & $A=3.263,45 \mathrm{~m}^{2}$ & $6,65 \%$ \\
\hline & ÁREA DE ÁGUA & $18,18 \mathrm{~m}^{2}$ & $0,04 \%$ \\
\hline & TOTAL & $A=49.097,00 \mathrm{~m}^{2}$ & $100,00 \%$ \\
\hline & \multicolumn{2}{|c|}{ ALTITUDE DO PONTO MONITORADO } & $889,30 \mathrm{~m}$ \\
\hline & & $0 \mathrm{~m}$ & $1000 \mathrm{~m}$ \\
\hline
\end{tabular}

Figura 02. Análise quantitativa do uso do solo - 2005.

Tabela 01 - Uso do solo dos pontos monitorados dez.2004-jan.2005

\begin{tabular}{ll}
\hline LOCAL & LEI DE USO E OCUPAÇÃO DO SOLO (10/2004) \\
\hline Industrial 01 & Setor Industrial e de Serviços - Rua Tavares de Lyra \\
Industrial 02 & Setor Industrial e de Serviços - Rua Tavares de Lyra \\
Residencial 03 & Zona Residencial 04 - Vila Local \\
Residencial 04 & Zona Residencial 04 - Vila Coletora \\
Centro 05 & Zona Central - Via Central \\
Centro 06 & Zona Central - Via Arterial \\
Residencial 07 & Zona Residencial 04 - Vila Local \\
Residencial 08 & Zona Residencial 04 - Vila Coletora \\
\hline
\end{tabular}

Foram utilizadas fotos aéreas na escala 1:8000 e bases planialtimétricas, na escala 1:10.000, em meio digital, do vôo do ano de 1999, cedidas pela Prefeitura Municipal de São José dos Pinhais. Para complementar a análise, foram realizadas visitas nos locais de implantação dos abrigos e no seu entorno, objetivando dirimir dúvidas quanto aos tipos de ocupação ou revestimentos existentes no local. Foram então determinados cinco tipos de ocupações ou revestimentos: área construída, área impermeabilizada (calçadas, ruas pavimentadas), área verde (bosques ou matas), área livre (gramados, pedriscos, plantações, terra) e área com a presença de água (rios, lagos, córregos, piscinas). 
Tabela 02 - Porcentagens dos padrões de uso do solo para o raio de 125 metros - dez.2004-jan.2005

\begin{tabular}{lllllllll}
\hline USO DO SOLO & \multicolumn{7}{c}{ ABRIGOS/ PORCENTAGENS DE OCUPAÇÃO (\%) } \\
& 1 & 2 & 3 & 4 & 5 & 6 & 7 & 8 \\
\hline Á.Construída & 19,96 & 29,70 & 30,49 & 30,9 & 27,4 & 34,69 & 10,45 & 22,95 \\
Á. Livre & 54,77 & 51,72 & 29,36 & 37,95 & 26,58 & 24,82 & 44,17 & 44,91 \\
Á. Pavimentada & 16,14 & 16,26 & 39,06 & 25,77 & 39,06 & 36,94 & 12,34 & 25,45 \\
Á. Verde & 4,89 & 2,32 & 1,08 & 5,38 & 6,8 & 3,54 & 33,04 & 6,65 \\
Á. Água & 4,23 & 0 & 0 & 0 & 0,16 & 0 & 0 & 0,04 \\
\hline
\end{tabular}

Tabela 03 - Porcentagens dos padrões de uso do solo para o raio de 56 metros dez.2004-jan.2005

\begin{tabular}{lllllllll}
\hline PADRÕES DE & \multicolumn{7}{c}{ ABRIGOS/ PORCENTAGENS DE OCUPAÇ̃̃O (\%) } \\
USO DO SOLO & 1 & \multicolumn{1}{c}{ ( } & 3 & 4 & 5 & 6 & 7 & \multicolumn{1}{c}{8} \\
\hline Á. Construída & 10,24 & 39,35 & 38,58 & 23,83 & 40,83 & 45,01 & 16,90 & 35,72 \\
Á. Livre & 65,32 & 43,98 & 26,85 & 26,45 & 30,07 & 17,85 & 42,94 & 35,73 \\
Á. Pavimentada & 21,37 & 14,77 & 34,57 & 30,89 & 27,69 & 33,09 & 18,23 & 25,42 \\
Á.Verde & 3,07 & 1,90 & 0,00 & 18,83 & 1,41 & 4,06 & 21,94 & 2,95 \\
Á. Água & 0,00 & 0,00 & 0,00 & 0,00 & 0,00 & 0,00 & 0,00 & 0,18 \\
\hline
\end{tabular}

Para analisar a relação entre as variáveis da temperatura e dos atributos mensurados, foram elaboradas regressões lineares simples entre os componentes. Para este cálculo, utilizou-se a temperatura média de cada ponto associada aos atributos mensurados. Esse procedimento foi repetido para o período da manhã, tarde, noite e madrugada, pelo fato da temperatura do ar comportar-se de forma diferenciada ao longo do dia. Os produtos dessa regressão, os "R-quadrados", traduzem o quanto as variáveis estão relacionadas (quanto mais próximo de um, melhor a relação entre as variáveis).

\section{RESULTADOS}

Observando a tabela 04, resultante das médias das temperaturas do ar obtidas por meio do monitoramento, é possível verificar os pontos que registraram as maiores e as menores temperaturas.

Comparando entre si as temperaturas médias nos pontos, no período da manhã, percebeu-se claramente a predominância de dois grupos similares entre si, que foram: os pontos Industrial 02, Central 05, Central 06 e Residencial 07, no grupo com as menores diferenças de temperatura em relação ao Ponto de Controle (Aeroporto Afonso Pena) e os pontos Industrial 01, Residencial 03, Residencial 04, Residencial 08, com as maiores diferenças de temperatura entre os mesmos e o Ponto de Controle.

Para o período da tarde, a similaridade das variações entre os pontos se mantiveram, embora os contrastes passaram a ser maiores, como era previsto para esse turno, quando ocorre maior aquecimento dos materiais e superfícies urbanas. Agrupando os valores apresentados na tabela 04, para o período da tarde, verifica-se a predominância de três padrões de pontos, ou seja: diferenças de temperatura média entre o ponto monitorado de igual ou superior a $3^{\circ} \mathrm{C}$ (Industrial 01, Residencial 03, Residencial 07 e Residencial 08), diferenças de $2^{\circ} \mathrm{C}$ ou mais (Industrial 02, Residencial 04) e diferença de $1,2{ }^{\circ} \mathrm{C}$ ou mais (Central 05 e Central 06). 
Tabela 04 - Temperaturas médias registradas nos pontos monitorados para os períodos- dez.2004 - jan. 2005

\begin{tabular}{|c|c|c|c|c|}
\hline \multicolumn{5}{|c|}{ LOCALIZAÇÃO DOS PONTOS MONITORADOS } \\
\hline PERÍODO & $\begin{array}{c}\text { Industrial } \\
1\end{array}$ & $\begin{array}{c}\text { Industrial } \\
2\end{array}$ & $\begin{array}{c}\text { Residencial } \\
3\end{array}$ & $\underset{4}{\text { Residencial }}$ \\
\hline MANHÃ & 21,68 & 19,93 & 20,93 & 20,59 \\
\hline TARDE & 26,92 & 24,92 & 26,59 & 24,74 \\
\hline NOITE & 19,93 & 18,95 & 19,42 & 18,81 \\
\hline MADRUGADA & 17,58 & 16,86 & 16,79 & 16,70 \\
\hline \multicolumn{5}{|c|}{ LOCALIZAÇÃO DOS PONTOS MONITORADOS } \\
\hline PERÍODO & $\begin{array}{c}\text { Central } \\
5\end{array}$ & $\begin{array}{c}\text { Central } \\
6\end{array}$ & $\begin{array}{c}\text { Residencial } \\
7\end{array}$ & $\begin{array}{c}\text { Residencial } \\
8\end{array}$ \\
\hline MANHÃ & 20,02 & 19,61 & 20,02 & 21,58 \\
\hline TARDE & 24,76 & 23,89 & 27,12 & 27,26 \\
\hline NOITE & 20,18 & 18,48 & 20,92 & 20,25 \\
\hline MADRUGADA & 17,83 & 16,33 & 9,14 & 17,60 \\
\hline
\end{tabular}

A diferença entre os pontos monitorados é acentuada no período noturno devido às trocas térmicas entre os edifícios, que interferem no resfriamento do ar. Observando a tabela 04, é possível verificar a predominância de dois padrões da diferença da temperatura do ar em relação ao ponto de controle, o primeiro com valores iguais ou maiores que $1^{\circ} \mathrm{C}$ (Residencial 03, Central 05, Residencial 07 e Residencial 08) e o segundo com valores menores que $1^{\circ} \mathrm{C}$ (Industrial 01, Industrial 02, Residencial 04 e Central 06).

Para a madrugada, os valores de temperatura média nos pontos obedeceram a um mesmo padrão, quase não sendo percebidas diferenças entre os pontos. Isso ocorreu porque o resfriamento já estava instalado, reforçandose nesse turno o resfriamento do ar mais acentuadamente, fazendo as diferenças entre os pontos diminuírem.

Quanto aos resultados obtidos por meio da análise de regressão linear simples, de acordo com a tabela 05, de uma maneira geral, os coeficientes de determinação entre as variáveis dependentes e independentes apresentaram baixa correlação. Isto pode estar associado à interferência do sombreamento nas áreas mais adensadas e ao padrão de ocupação característico de São José dos Pinhais, com grande quantidade de áreas verdes e livres e pouca verticalização.

No período noturno, para o raio de 125 metros (tabela 05), o coeficiente de determinação entre as temperaturas e a as áreas construídas quantificadas, obteve a melhor resposta dentre todas as medições, tendo como "r-quadrado" o valor 0,7847. Esse coeficiente por estar próximo do número um, indica que as variáveis associadas possuem boa correlação, além de refletir a maior influência do espaço construído no período noturno e confirmar a literatura pesquisada. Ainda para o mesmo raio, encontrou-se o coeficiente de 0,4884 para a área verde, fato que pode ser associado ao papel fundamental da vegetação à noite, período característico de resfriamento devido ao processo de evapotranspiração, que umidifica o ar através da liberação de vapor d'água.

Para o período da tarde, período de maior aquecimento do dia, de acordo com a tabela 05, para o raio maior, o melhor coeficiente de determinação, 
0,5728, ocorreu para a área construída. Esse fato pode estar associado a estocagem de calor característica desse período.

Tabela 05 - Coeficientes de determinação, para o período da manhã, tarde, noite e madrugada

\begin{tabular}{|c|c|c|c|c|c|c|c|c|}
\hline \multirow[b]{2}{*}{ ATRIBUTO } & \multicolumn{2}{|c|}{ MANHÃ } & \multicolumn{2}{|c|}{ TARDE } & \multicolumn{2}{|c|}{ NOITE } & \multicolumn{2}{|c|}{ MADRUGADA } \\
\hline & $\begin{array}{l}\text { R2 } \\
\text { (Raio } \\
125 \mathrm{~m} \text { ) }\end{array}$ & $\begin{array}{l}\text { R2 } \\
\text { (Raio } \\
56 \mathrm{~m} \text { ) }\end{array}$ & $\begin{array}{l}\text { R2 } \\
\text { (Raio } \\
125 \mathrm{~m} \text { ) }\end{array}$ & $\begin{array}{l}\text { R2 } \\
\text { (Raio } \\
56 \mathrm{~m} \text { ) }\end{array}$ & $\begin{array}{l}\text { R2 } \\
\text { (Raio } \\
125 \mathrm{~m} \text { ) }\end{array}$ & $\begin{array}{l}\text { R2 } \\
\text { (Raio } \\
56 \mathrm{~m} \text { ) }\end{array}$ & $\begin{array}{l}\text { R2 } \\
\text { (Raio } \\
125 \mathrm{~m} \text { ) }\end{array}$ & $\begin{array}{l}\text { R2 } \\
\text { (Raio } \\
56 \mathrm{~m} \text { ) }\end{array}$ \\
\hline Área Construída (\%) & 0,0668 & 0,0668 & 0,5728 & 0,3102 & 0,7847 & 0,2030 & 0,6513 & 0,2025 \\
\hline Área Livre (\%) & 0,2191 & 0,2191 & 0,2701 & 0,3283 & 0,0777 & 0,2094 & 0,1209 & 0,3067 \\
\hline $\begin{array}{l}\text { Área Pavimentada } \\
(\%)\end{array}$ & 0,0314 & 0,0314 & 0,1963 & 0,0919 & 0,119 & 0,1671 & 0,1256 & 0,2354 \\
\hline Área Verde (\%) & 0,049 & 0,049 & 0,1702 & 0,0083 & 0,4884 & 0,0490 & 0,308 & 0,0141 \\
\hline
\end{tabular}

Quanto aos resultados obtidos por meio da análise de regressão linear simples, é possível perceber que a melhor relação ocorreu para o raio maior. Esse resultado confirma as análises de Rossi(2004) nas medições de Curitiba, para o raio de abrangência maior, além de reafirmar a literatura quanto a associação da área construída com a temperatura do ar. As correlações com os demais atributos apresentaram valores distantes de um, ou seja, pouca relação entre as variáveis relacionadas.

De uma maneira geral as correlações apresentaram-se baixas, o que de acordo com a literatura demonstra que não ocorre influência dos atributos mensurados na temperatura. O fato de não ter havido boa correlação estatística, pode estar associado à seleção do método adotado, ou seja, a análise de regressão pode não ser a melhor ferramenta para a análise de dados como os dessa pesquisa ou devido a possível interferência de outras variáveis não consideradas. A baixa correlação também pode ser associada as divergências encontradas entre a foto aérea e a base planialtimétrica, que resultaram nas porcentagens dos atributos urbanos.

Essas considerações são decorrentes das análises dos atributos mensurados isoladamente, ou seja, desconsiderando suas interferências mútuas. Também não foram consideradas as condições meteorológicas dos dias de monitoramento, que exercem influência importante sobre as relações entre os atributos urbanos e as temperaturas encontradas.

\section{CONCLUSÕES}

O presente artigo procurou avaliar o uso da análise de regressão linear simples para demonstrar a relação entre a temperatura do ar e os padrões de ocupação urbana na cidade de São José dos Pinhais/PR. Com isso, não procurou uniformizar os resultados para todo o município ou determinar uma equação matemática de aplicação para o planejamento urbano, mas sim estabelecer uma tendência de relação entre os parâmetros de ocupação e as variações de temperatura decorrentes da ocupação urbana. 
Esta pesquisa é pioneira em São José dos Pinhais e secundariamente na Região Metropolitana de Curitiba, o que significa dizer que há muito ainda a ser estudado sobre o assunto, principalmente se forem consideradas as altas taxas de crescimento populacional dos municípios que a compõe. Associado a isso, as questões relacionadas ao clima urbano ainda são controversas, devido à complexidade dos fenômenos que ocorrem nos centros urbanos. A hipótese de existir diferenciação na temperatura de São José dos Pinhais decorrente do padrão urbano de ocupação progressivamente adensado continua em questão e necessita de novos estudos para ser melhor interpretada.

Entretanto, o monitoramento da temperatura do ar durante os trinta dias considerados, permitiu detectar que a área urbana de São José dos Pinhais em relação ao campo térmico formado, considerando as alterações dos ambientes naturais pelos padrões de uso do solo, favorece as diferenças de armazenamento e estocagem de calor, que induzem a formação de Ilhas de Calor. Os resultados indicam também que as formas de ocupação urbana e a temperatura do ar apresentam relações estreitas, porém, de acordo com a literatura e com os resultados encontrados, não são lineares ou constantes ao longo do tempo. Isso pode ser evidenciado observando a complexidade do sistema e os vários agentes que atuam e interferem nessa relação.

As análises dos campos térmicos demonstraram a ocorrência de Ilhas de Calor, na pesquisa considerados os valores da temperatura do ar de maior destaque, em algumas localidades da área urbana e que essas podem estar relacionadas aos padrões de ocupação urbana. As Ilhas de Calor de maior intensidade, da ordem de $7^{\circ} \mathrm{C}$ foram observadas principalmente nos pontos Industrial 01 e Residencial 03, sob a ação de Massa Polar Atlântica. As Ilhas de Calor de média intensidade, aproximadamente $5^{\circ} \mathrm{C}$, foram verificadas nos pontos Residencial 03 e Residencial 07, sob a ação de Massa Polar Velha. E por fim, as Ilhas de Calor de intensidade fraca ou moderada, com diferenças de $2,50^{\circ} \mathrm{C}$, foram observadas nos pontos Industrial 01 e Residencial 08, sob a atuação de Frente Polar Atlântica.

Com base nos resultados encontrados percebe-se que não ocorreram Ilhas de Calor de intensidade alta ou média nos pontos centrais. Esse fato pode estar associado, entre outros fatores, ao padrão próprio de ocupação do centro de São José dos Pinhais, ou seja, edificações térreas, não verticalizadas, grande porcentagem de áreas verdes e livres. Nesse contexto e baseado na tendência de adensamento dos centros urbanos, o presente trabalho vem contribuir, no campo do planejamento e da gestão urbana, nas decisões futuras, para que através da definição cuidadosa dos parâmetros de ocupação, não ocorram mudanças significativas na temperatura do ar dos ambientes urbanos.

\section{REFERÊNCIAS}

ELNAHAS, M. M.. How do planners and architects deal with conflicting climate design objectives? In: CONGRESSO PLEA: Sustentando o futuro: Energia Do Ambiente - Ecology,16., 1999, Austrália. Anais eletrônicos... Disponível em <http://www. infohab.org.br > Acesso em: 10 de mar. 2003.

GARCIA, M. C.M. Estudio del clima urbano de Barcelona: la "isla de calor". Barcelona, 1992. Tese (Doutorado do Departamento de Geografia Física) - 
Universidade de Barcelona, 193p.

IPARDES, IBGE. Projeções das populações municipais por sexo e idade 2000 a 2010. Curitiba: IPARDES, IBGE, 1999.

- Indicadores e mapas temáticos para o planejamento urbanos e regional: Paraná 2003. IPARDES, 2003. 1 CD-ROM.

KATZSCHNER, L. The Urban Climate as a Parameter for Urban Development. Journal of Energy and Buildings, Netherlands, 1988, v.11, n.13, p. 137-147. Disponível em < http://www.periodicos.capes.gov.br> Acessado em 15 de mar. 2003.

MAACK, R. Geografia física do estado do Paraná. Curitiba: Atlas, 1968. 350p.

MASCARÓ, L. A. R. Energia na edificação: estratégia para minimizar seu consumo. São Paulo: Projeto Editores Associados, 1985-1986, v. 2. 213p.

MENDONÇA, F. A. O clima e o planejamento urbano de cidades de porte médio e pequeno. São Paulo, 1994. Tese (Doutorado em Geografia) Universidade de São Paulo.

MONTEIRO, C.A.; MENDONÇA, F. (org.). Clima urbano. São Paulo: Contexto, 2003. 192p.

MONTEIRO, C.A. Adentrar a Cidade para tomar-lhe a temperatura. Geosul, Florianópolis, v.1, n. 9, p. 2-19, 1990.

OKE, T. R., JOHNSON, G. T; STEYN, G; WATSON, I.D. Simulation of nocturnal surface urban heat islands under 'ideal' conditions: Part 2 . diagnosis of causation. Journal of Boundary-Layer Meteorology, 1991, v. 56, p. 339358. Disponível em < http://www.periodicos.capes.gov.br> Acessado em 15 de mar. 2003.

ROMERO, M. A. B. Arquitetura bioclimática do espaço público. Brasília:UNB, 2001. 225p.

ROSSI, F.A. Análise da influência da ocupação do solo na variação da temperatura em diferentes localidades da cidade de Curitiba. Curitiba, 2004. Dissertação (Mestrado em Tecnologia) - Centro Federal de Educação Tecnológica do Paraná.

SÃO JOSÉ DOS PINHAIS. Lei n.10, de 30 de dezembro de 2004. Dispõe sobre o zoneamento, uso e ocupação do solo e sistema viário do município de São José dos Pinhais e dá outras providências. Jornal São José dos Pinhais Metrópole, edição no 827. 